Article

\title{
Geographical Variability Affects CCHFV Detection by RT-PCR: A Tool for In-Silico Evaluation of Molecular Assays
}

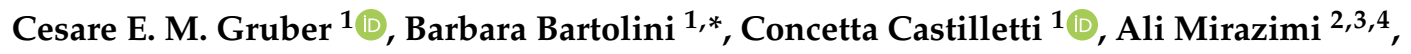 \\ Roger Hewson $^{5}$, Iva Christova ${ }^{6}$ (D), Tatjana Avšič ${ }^{7}$ (D), Roland Grunow ${ }^{8}$, Anna Papa ${ }^{9}$, \\ María P. Sánchez-Seco ${ }^{10}$, Marion Koopmans ${ }^{11}$, Giuseppe Ippolito ${ }^{1} \mathbb{D}$, Maria R. Capobianchi ${ }^{1}$, \\ Chantal B. E. M. Reusken ${ }^{11,12}$ and Antonino Di Caro ${ }^{1}$ (D)
}

1 National Institute for Infectious Diseases (INMI) “L. Spallanzani” IRCCS, WHO Collaborating Center for clinical care, diagnosis, response and training on Highly Infectious Diseases, 00149 Rome, Italy; cesare.gruber@inmi.it (C.E.M.G.); concetta.castilletti@inmi.it (C.C.); giuseppe.ippolito@inmi.it (G.I.); maria.capobianchi@inmi.it (M.R.C.); antonino.dicaro@inmi.it (A.D.C.) Public Health agency of Sweden, 17182 Solna, Sweden; ali.mirazimi@folkhalsomyndigheten.se National veterinary Institute, 75189 Uppsala, Sweden

4 Department of laboratory Medicine, Clinical Microbiology, Karolinska Institute and Karolinska, 17177 Stockholm, Sweden

5 Public Health England, National Infection Service WHO Collaborating Centre for Virus Reference and Research (Special Pathogens) Porton Down, Salisbury SP40JG, UK; Roger.Hewson@hpa.org.uk

6 National Reference Laboratory on Vector-Borne Pathogens, Leptospira and Listeria, Microbiology Department, National Center of Infectious and Parasitic Diseases, 1504 Sofia, Bulgaria; iva_christova@yahoo.com

7 Faculty of Medicine, Institute of Microbiology and Immunology, 1000 Ljubljana, Slovenia; Tatjana.Avsic@mf.uni-lj.si

8 Centre for Biological Threats and Special Pathogens, Highly Pathogenic Microorganisms (ZBS 2), Robert Koch Institute, 13353 Berlin, Germany; GrunowR@rki.de

9 Department of Microbiology, Medical School, Aristotle University of Thessaloniki, 54124 Thessaloniki, Greece; annap@med.auth.gr

10 National Centre of Microbiology, Institute of Health “Carlos III”, Majadahonda, 28220 Madrid, Spain; paz.sanchez@isciii.es

11 Erasmus MC, Department of Viroscience, WHO Collaborating Centre for arbovirus and viral hemorrhagic fever reference and research, 3015 CN Rotterdam, The Netherlands; m.koopmans@erasmusmc.nl (M.K.); c.reusken@erasmusmc.nl (C.B.E.M.R.)

12 Centre for Infectious Disease Control, National Institute for Public Health and the Environment, 3721 MA Bilthoven, The Netherlands

* Correspondence: barbara.bartolini@inmi.it; Tel.: +39-06-5517-0685

Received: 8 October 2019; Accepted: 15 October 2019; Published: 16 October 2019

check for updates

\begin{abstract}
The Crimean-Congo hemorrhagic fever virus (CCHFV) is considered to be a major emerging infectious threat, according to the WHO R\&D blueprint. A wide range of CCHFV molecular assays have been developed, employing varied primer/probe combinations. The high genetic variability of CCHFV often hampers the efficacy of available molecular tests and can affect their diagnostic potential. Recently, increasing numbers of complete CCHFV genomic sequences have become available, allowing a better appreciation of the genomic evolution of this virus. We summarized the current knowledge on molecular methods and developed a new bioinformatics tool to evaluate the existing assays for CCHFV detection, with a special focus on strains circulating in different geographical areas. Twenty-two molecular methods and 181 sequences of CCHFV were collected, respectively, from PubMed and GenBank databases. Up to 28 mismatches between primers and probes of each assay and CCHFV strains were detected through in-silico PCR analysis. Combinations of up to three molecular methods markedly decreased the number of mismatches
\end{abstract}


within most geographic areas. These results supported the good practice of CCHFV detection of performing more than one assay, aimed for different sequence targets. The choice of the most appropriate tests must take into account patient's travel history and geographic distribution of the different CCHFV strains.

Keywords: CCHFV; molecular detection; Crimean-Congo hemorrhagic fever virus; arthropod-borne virus; laboratory preparedness; emerging diseases

\section{Introduction}

The Crimean-Congo hemorrhagic fever virus (CCHFV) is a tick-borne, negative-sense, single-stranded RNA orthonairovirus, and the causative agent of the Crimean-Congo hemorrhagic fever (CCHF). The CCHFV is considered to be one of the major emerging infectious threats as it might cause a severe disease, with increasing number of cases of infection in Africa, Middle East, Asia, and parts of Europe [1,2].

Rapid diagnosis is crucial to ensure the implementation of appropriate infection control measures and guide post exposure prophylaxis [3]. Among the diagnostic tests available, reverse-transcriptase PCR (RT-PCR) is the method of choice for rapid laboratory diagnosis during the acute phase of infection [4]. However, the efficacy of the available molecular tests is hampered by the high genetic variability of the virus that displays the greatest degree of sequence diversity of any arbovirus species $[4,5]$.

CCHFV is an enveloped virus with a tripartite [small (S), medium (M), and large (L)] negative-sense single strand RNA genome [6], characterized by a degree of sequence diversity of $20 \%, 22 \%$, and $31 \%$ among the S-, L-, and M-segments of the virus genome [5]. The mechanisms responsible for this marked degree of sequence diversity include genetic drift or separate evolution of lineages in geographically constrained reservoirs. Long-distance transport in infected ticks by migratory birds, or trade in viremic life stock can result in multiple strain variants occurring in the same endemic area. Segment reassortment as a result of co-infection can also increase the diversity of CCHFV strains $[4,7,8]$.

Based on geographical origin and phylogenetic analyses of the $\mathrm{S}$ gene segment, CCHFV has been previously classified into six main geographical clades [4] - three predominantly diffused in Africa (Clades I-III) [9,10], two in Europe (Clades V and VI) [11-13], and one in Asia (Clade IV) [14-17].

Most of the isolates causing outbreaks in Eastern Europe belong to Clade V, whereas Clade VI includes largely divergent strains isolated from ticks in Greece (including the strain AP92) [4,18] and Turkey [19]. Isolates belonging to the "African" Clade III were also collected in Spain from infected ticks in 2010 [20] and during 2011-2015 [21], which were found to have caused human infections in 2016 [22]. One more recent human infection in Spain in 2018 were caused by a CCHFV not yet characterized [23].

Moreover, in some cases, different CCHFV geographic clades are characterized by different pathogenic potentials, as in the case of Clade VI in Greece, where, despite high antibody prevalence, very few and mostly mild human cases have been reported [24].

Viral diversity can strongly affect sensitivity of molecular tests when mutations occur at the binding site of primers and probes [25]. In particular, mismatches occurring within the $3^{\prime}$-end can dramatically affect fragment amplification [26,27].

Experimental validation of molecular methods can usually be performed on a limited set of biological samples that might not be representative of the viral population from the different outbreak-prone geographical areas. Nowadays, the increasing number of complete viral sequences that can be retrieved from public databases provide a worthwhile resource for evaluating the genetic variation within viral strains. However, many sequence entries have been assembled using classic RT-PCR approaches and the use of general terminal sequencing primers; as a consequence, published sequence fragment termini often include primer sequences. Very few segments have been assembled 
using molecular techniques specific for terminal sequencing, such as rapid amplification of cDNA ends (RACE).

Many tools were developed for designing in-silico PCR methods [28,29]. Here, we describe a bioinformatic tool (CCHFV Primer Checker) to evaluate the detection efficacy of the existing molecular assays and to propose specific sets of assays to detect as many CCHFV strains from all geographic regions, as possible.

\section{Materials and Methods}

\subsection{Data Collection}

Molecular methods included in this analysis were obtained by a web-search in PubMed or were directly indicated by the authors. A deliberately relaxed query was done to capture a larger-than-required set of articles. The query included the terms "CCHF", "CHF", "CCHFV", "CHFV", "Congo virus", or "Crimean-Congo"; filtered by the possibilities of "molecular diagnostics", "molecular method", "molecular testing", "PCR", "RT-PCR", "real time PCR", "NAT", "NAAT", "LAMP","TMA", or "transcription-mediated amplification".

All CCHFV genomes available by 31 December 2018 were retrieved from the GenBank (https://www.ncbi.nlm.nih.gov/nucleotide/), using "txid1980519[Organism]" as the term of query. All S segments including the complete coding region, with available data about host, collection country, and collection date were selected. The $S$ segment sequence of the CCHFV that caused a case of infection in Spain in 2018 [23] was also added to the analysis, although the sequence was not complete [30].

\subsection{Phylogenetic Analysis}

The analyses was focused on the $S$ segment, as the most conserved segment across the CCHFV clades [5,31], and the main target for molecular assays. CCHFV complete coding sequences of the S segment from the different viral strains were selected and clustered at $100 \%$, with CD-HIT v4.6; all sequences were then aligned with MAFFT v7.123b in the local pair mode. Phylogenetic analysis was performed after removing all positions with gaps in the alignment; the maximum likelihood tree was then obtained with RAxML v8.2.10 using the GTRGAMMA model and 1000 bootstrap inferences. Moreover, pairwise distances between sequences were calculated using the Kimura model. In agreement with previous works, branch positions, pairwise distances, and collection countries were used to identify separate CCHFV clades within the phylogenetic tree [5,9-22].

\subsection{Software Description}

The homemade python script, named "CCHFV Primer Checker", took the primers/probes listed in a table in the "csv" format, the multi-sequence alignment file in the "fasta" format, and, for each clade, the list of GeneBank accession numbers of all sequences to be analyzed, in the "txt" format. Both software and input files for the CCHFV analysis are posted in GitHub (https://github.com/cesaregruber/CCHFV-PrimerChecker).

As most heuristic alignment algorithms have difficulties in recovering the ends of the alignment region, when these contain mismatches [32], the "CCHFV Primer Checker" searched for primers and probe binding sites using a perfect-match approach with IUPAC ambiguity codes [33]. If the assay contained degenerate primers, the ambiguous characters were replaced by regular expressions (for example, the ambiguous character " $N$ " is substituted by regular nucleotides $A+C+G+T$ ). The software found the start and end positions of the annealing sites of each primer and probes, with respect to IbAr10200 (NCBI reference sequence NC_005302).

The number and position of mismatches for every primer/probe with each CCHFV sequence was recorded by the program. The software calculated the percentage of mismatches between each primer/probe and all targets belonging to the same viral clade. The percentage of viral strains in each 
clade fully matching the primers and probe set (i.e., with no mismatch in the annealing sites) was also calculated.

The results were then displayed as an Excel file, reporting the frequency of mismatches between each primers/probe set and every genome sequence, for each clade. As it is known that a single $3^{\prime}$-end mismatch can affect the performance of the primers [26,27,32], all those "critical mismatches" occurring at the last five positions of the 3 '-end primers were also recorded and reported.

To investigate the detection efficacy of a combination of assays, the software also evaluated the number of mismatches of all viral sequences in each clade with all possible assay combinations, with a maximum of five assays per combination.

\subsection{Assays Evaluation}

In order to guide the interpretation of the results of the in-silico analysis, for each viral clade three threshold parameters were assumed:

1. The primers/probe set of the assay must not have had more than 3 mismatches with respect to every genome in the clade;

2. The primers of the assay must not have had more than 1 critical mismatch, i.e., a mismatch located at the last 5 positions of 3 '-end;

3. Within a clade, more than $50 \%$ of viral strains must have had fully matched the primers/probe set (therefore, we could expect that new sequences owing to the same clade would not have too many mismatches).

For each analyzed assay, the maximum number of mismatches of the respective primers/probe set, as well as that for each component of the set, were reported, together with the percent number of viral strains that fully matched each assay.

For each clade, the assay combination(s) with the minimum number of mismatches with all viral sequences was also reported.

\section{Results}

\subsection{Data Collection}

The number of CCHFV molecular detection articles collected through PubMed search was 206 (Figure 1), most of them were discarded as they did not report detailed descriptions of the detection methods employed, including the sequences of primers and probes.

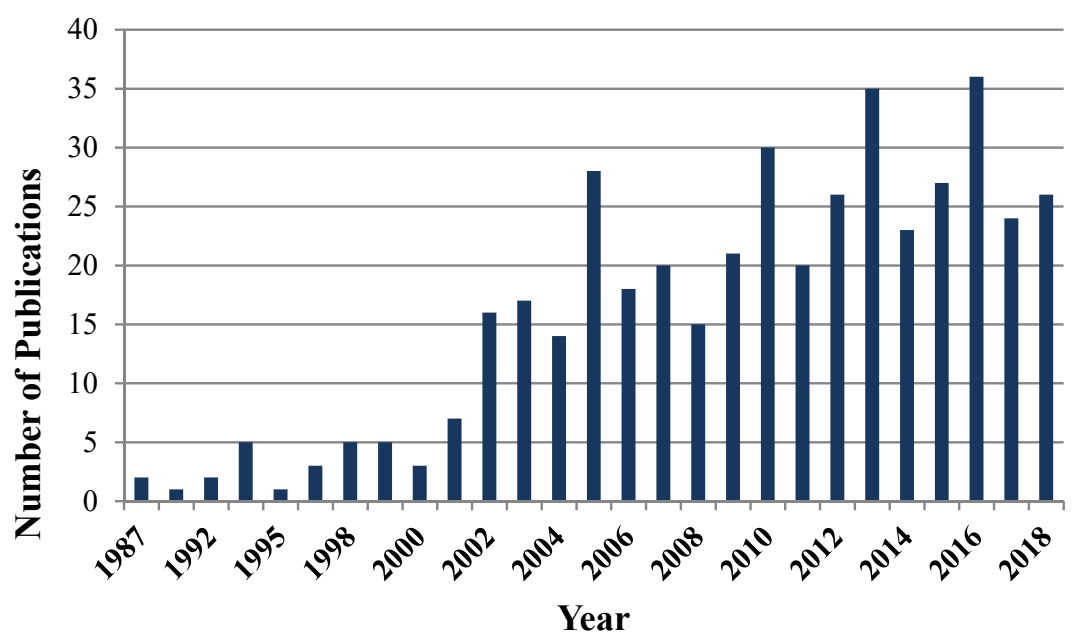

Figure 1. Publications on Crimean-Congo hemorrhagic fever virus (CCHFV). Frequency of CCHFV molecular diagnostics publications in English from 1992 to 2018. 
The complete list of published molecular assays published until December 2018 includes 2 single round PCR [34,35], 6 nested PCR [22,36-39], 12 real-time PCR [40-51], 1 LAMP [52]; and 1 RPA (Recombinase Polymerase Amplification) [53]. All assays are reported in Table 1 and in Supplementary Table S1. When available, reference testing materials and sensitivity/specificity of the methods are also reported in Table 1.

Starting with 2729 CCHFV sequences available in GenBank, 1,438 were found as the S segment, and 263 as complete coding sequences. The selection of records with available data about host, collection country and date, and clustering at $100 \%$ of nucleotide identity provided a total of 181 strains.

Table 1. Molecular assays for CCHFV detection published until 2018. For each assay, the type of molecular assay, the publication's first author, the publication year, reference testing materials, and sensitivity/specificity of the tests are reported.

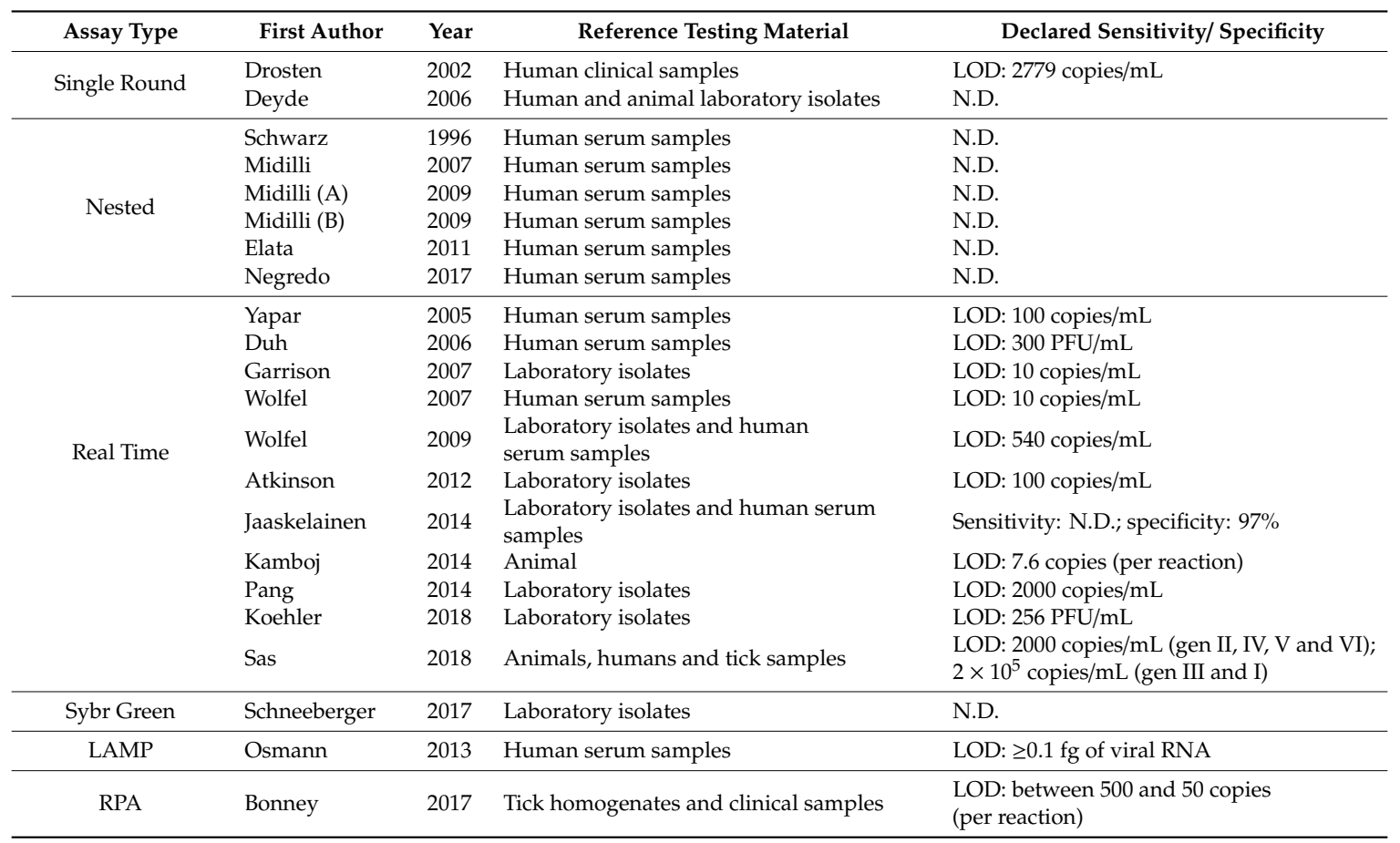

N.D.—not declared; LOD—limit of detection.

\subsection{Phylogenetic Analysis}

The phylogenetic tree built with all 181 complete coding sequences of the $S$ segment is shown in Figure 2. Our analysis suggests a clade separation into nine groups. In agreement with previous studies [5], we maintained the nomenclature of six different clades previously recognized, corresponding to different geographic regions-three clades prevalently diffused in Africa (Clades I-III), and two in Europe (Clades V and VI) and Asia (Clade IV). Moreover, one recently described clade was identified as clade VII [4] and, following previous work indications, clades III and IV were split into sub-groups, according to divergence in genetic distance (see web-only Supplementary Table S2) [17]. Median distance among CCHFV S sequences was 0.12 (range: $0.00-0.22$ ), which was in agreement with [5]. The detailed phylogenetic tree is reported in the web-only Supplementary Figure S1. 


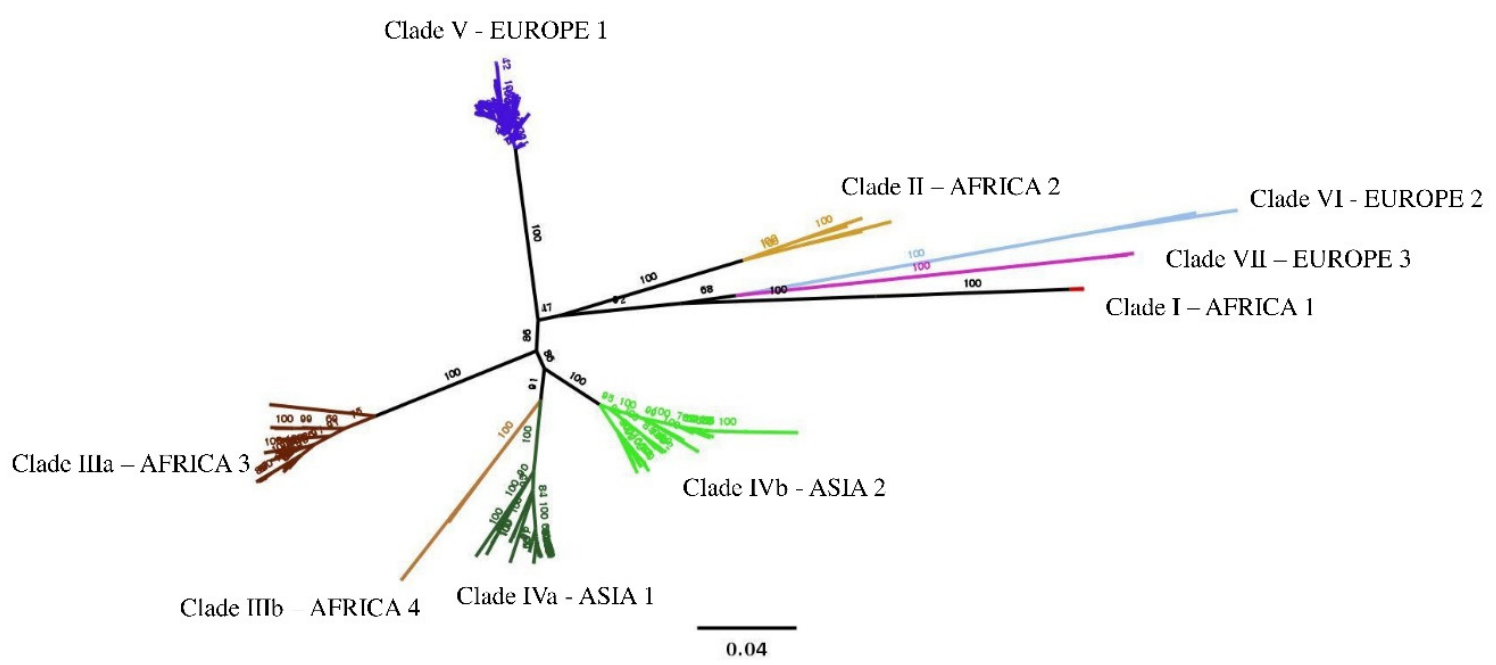

Figure 2. Maximum Likelihood Phylogenetic tree for complete S segment of CCHFV. Branches belonging to different clades are presented in different colors. Clade separation was adopted, in agreement with previous works (see Results), on the basis of collection countries and phylogeny. Asia 1: Oman, Iran Pakistan, Afghanistan, Kazakhstan, and United Arab Emirates; Asia 2: Iran, India, Tajikistan, Uzbekistan, Turkmenistan, China, and United Arab Emirates; Europe 2: Greece; Europe 3: Russia; Africa 3: Central and South Africa, and Spain; Africa 4: Nigeria and Spain.

\subsection{Assays Evaluation}

Using the CCHFV Primer Checker workflow, all sequence variants of CCHFV S segment versus the primers/ probe sets were identified for each molecular assay; reported in Supplementary Figure S2. The percentage of viral strains in each clade that fully matched (100\% nucleotide identity) the set is reported in Table 2. For each viral clade, molecular assays that showed matching results over the thresholds values described in Methods, are reported in bold. As some molecular tests have an annealing site that lies in the extreme $5^{\prime}$ or $3^{\prime}$ non-coding regions, which is not represented in all of the analyzed S segments, the number of sequences included in the analysis varied between 89 and 160, according to the location of the primer/probe alignments. Therefore, for the assays falling in this category, we restricted the analysis to a reduced subset of CCHFV sequences. These results are presented in Table 3, since the value of this analysis is reduced and cannot be directly compared to the results reported for the other assays in Table 2. 
Table 2. Scoring summary of the molecular assays. For each clade the number of mismatches between the best primer/probe set and the most divergent sequence is reported. The apostrophes indicate the presence of one or more critical mismatches. The percentage of sequences with no mismatches are shown are shown in brackets. The best results (i.e., over all threshold parameters-see Methods) are shown in bold.

\begin{tabular}{|c|c|c|c|c|c|c|c|c|c|c|c|}
\hline Type & Assay & $\begin{array}{l}\text { Prim / } \\
\text { Prob }\end{array}$ & & & & & Clade & & & & \\
\hline & & & $\begin{array}{c}\text { Africa } 1 \\
N=2\end{array}$ & $\begin{array}{c}\text { Africa } 2 \\
N=5\end{array}$ & $\begin{array}{c}\text { Africa } 3 \\
N=29\end{array}$ & $\begin{array}{c}\text { Africa } 4 \\
N=2\end{array}$ & $\begin{array}{l}\text { Asia } 1 \\
N=30\end{array}$ & $\begin{array}{l}\text { Asia } 2 \\
N=33\end{array}$ & $\begin{array}{c}\text { Europe } 1 \\
N=76\end{array}$ & $\begin{array}{c}\text { Europe } 2 \\
N=2\end{array}$ & $\begin{array}{c}\text { Europe } 3 \\
N=2\end{array}$ \\
\hline $\begin{array}{l}\text { Single } \\
\text { Round }\end{array}$ & Drosten 2002 & 3 & $3(0.0 \%)$ & $5^{\prime}(0.0 \%)$ & $4(0.0 \%)$ & $3(0.0 \%)$ & $4(0.0 \%)$ & $2^{\prime}(60.6 \%)$ & $5(0.0 \%)$ & $9^{\prime}(0.0 \%)$ & $4(0.0 \%)$ \\
\hline \multirow{6}{*}{ Nested } & Schwarz 1996 & 4 & $5(0.0 \%)$ & $5^{\prime}(0.0 \%)$ & $7^{\prime}(0.0 \%)$ & $8^{\prime}(0.0 \%)$ & $11^{\prime}(0.0 \%)$ & $6^{\prime}(0.0 \%)$ & $5(0.0 \%)$ & $\begin{array}{c}13^{\prime \prime} \\
(0.0 \%)\end{array}$ & $12^{\prime}(0.0 \%)$ \\
\hline & Midilli 2007 & 3 & $5^{\prime}(0.0 \%)$ & $8^{\prime \prime}(0.0 \%)$ & $2^{\prime}(75.9 \%)$ & $9^{\prime}(0.0 \%)$ & $4^{\prime}(83.3 \%)$ & $1(84.8 \%)$ & $1(84.2 \%)$ & $4^{\prime}(0.0 \%)$ & $6^{\prime}(0.0 \%)$ \\
\hline & Midilli 2009 (A) & 4 & $\begin{array}{c}16^{\prime \prime} \\
(0.0 \%)\end{array}$ & $\begin{array}{c}20 " \\
(0.0 \%)\end{array}$ & $\begin{array}{c}21^{\prime \prime} \\
(0.0 \%)\end{array}$ & $\begin{array}{c}20^{\prime \prime} \\
(0.0 \%)\end{array}$ & $\begin{array}{c}21^{\prime \prime} \\
(0.0 \%)\end{array}$ & $\begin{array}{c}21^{\prime \prime} \\
(0.0 \%)\end{array}$ & $\begin{array}{c}21^{\prime \prime} \\
(0.0 \%)\end{array}$ & $4^{\prime}(50.0 \%)$ & $\begin{array}{c}16^{\prime \prime} \\
(0.0 \%)\end{array}$ \\
\hline & Midilli 2009 (B) & 4 & $\begin{array}{c}11^{\prime \prime} \\
(0.0 \%)\end{array}$ & $\begin{array}{c}10^{\prime \prime} \\
(0.0 \%)\end{array}$ & $\begin{array}{c}14^{\prime \prime} \\
(0.0 \%)\end{array}$ & $8^{\prime \prime}(0.0 \%)$ & $\begin{array}{c}12 " \\
(0.0 \%)\end{array}$ & $\begin{array}{c}11^{\prime \prime} \\
(0.0 \%)\end{array}$ & $4^{\prime}(71.1 \%)$ & $12^{\prime}(0.0 \%)$ & $\begin{array}{c}10^{\prime \prime} \\
(0.0 \%)\end{array}$ \\
\hline & Elata 2011 & 4 & $\begin{array}{c}11^{\prime \prime} \\
(0.0 \%)\end{array}$ & $10^{\prime}(0.0 \%)$ & $8^{\prime}(62.1 \%)$ & $12^{\prime}(0.0 \%)$ & $11^{\prime}(0.0 \%)$ & $11^{\prime}(0.0 \%)$ & $\begin{array}{c}10^{\prime \prime} \\
(0.0 \%)\end{array}$ & $\begin{array}{c}14^{\prime \prime} \\
(0.0 \%)\end{array}$ & $\begin{array}{c}14^{\prime \prime} \\
(0.0 \%)\end{array}$ \\
\hline & Negredo 2017 & 4 & $0(100 \%)$ & $\begin{array}{c}4^{\prime \prime} \\
(20.0 \%)\end{array}$ & $1(89.7 \%)$ & $4(0.0 \%)^{*}$ & $\begin{array}{c}3^{\prime \prime} \\
(80.0 \%)\end{array}$ & $2^{\prime}(87.9 \%)$ & $1(86.8 \%)$ & $0(100 \%)$ & $4(0.0 \%)$ \\
\hline \multirow{9}{*}{$\begin{array}{l}\text { Real } \\
\text { Time }\end{array}$} & Yapar 2005 & $2 / 1$ & $0(100 \%)$ & $1(40.0 \%)$ & $2(0.0 \%)$ & $2(0.0 \%)$ & $4^{\prime}(0.0 \%)$ & $1(60.6 \%)$ & $1(93.4 \%)$ & $2(0.0 \%)$ & $1(0.0 \%)$ \\
\hline & Duh 2006 & $2 / 1$ & $11^{\prime}(0.0 \%)$ & $7^{\prime}(0.0 \%)$ & $9^{\prime}(0.0 \%)$ & $5^{\prime \prime}(0.0 \%)$ & $8^{\prime}(0.0 \%)$ & $8^{\prime}(0.0 \%)$ & $3^{\prime}(25.0 \%)$ & $9^{\prime}(0.0 \%)$ & $7^{\prime}(0.0 \%)$ \\
\hline & Garrison 2007 & $2 / 1$ & $10^{\prime}(0.0 \%)$ & $4(0.0 \%)$ & $9^{\prime \prime}(0.0 \%)$ & $7^{\prime}(0.0 \%)$ & $9^{\prime \prime}(0.0 \%)$ & $5^{\prime}(12.1 \%)$ & $7^{\prime}(0.0 \%)$ & $\begin{array}{c}11^{\prime \prime} \\
(0.0 \%)\end{array}$ & $5^{\prime}(0.0 \%)$ \\
\hline & Wolfel 2007 & $2 / 2$ & $8^{\prime}(0.0 \%)$ & $6(0.0 \%)$ & $7^{\prime}(0.0 \%)$ & $4(0.0 \%)$ & $3(0.0 \%)$ & $4^{\prime}(9.1 \%)$ & $6^{\prime}(0.0 \%)$ & $6^{\prime}(0.0 \%)$ & $9(0.0 \%)$ \\
\hline & Wolfel 2009 & $6 / 13$ & $7(0.0 \%)$ & $8(0.0 \%)$ & $\begin{array}{c}6^{\prime \prime} \\
(24.1 \%)\end{array}$ & $2(0.0 \%)$ & $\begin{array}{c}3^{\prime \prime} \\
(73.3 \%)\end{array}$ & $5^{\prime \prime}(0.0 \%)$ & $5^{\prime}(0.0 \%)$ & $8^{\prime \prime}(0.0 \%)$ & $5(0.0 \%)$ \\
\hline & $\begin{array}{l}\text { Jaaskelainen } \\
2014\end{array}$ & $3 / 3$ & $4^{\prime \prime}(0.0 \%)$ & $6(0.0 \%)$ & $4(37.9 \%)$ & $6(0.0 \%)$ & $7^{\prime}(0.0 \%)$ & $7^{\prime}(0.0 \%)$ & $3^{\prime}(81.6 \%)$ & $4^{\prime \prime}(0.0 \%)$ & $6(0.0 \%)$ \\
\hline & Pang 2014 & $2 / 1$ & $9^{\prime}(0.0 \%)$ & $11(0.0 \%)$ & $3(3.4 \%)$ & $4^{\prime}(0.0 \%)$ & $3^{\prime}(0.0 \%)$ & $5^{\prime \prime}(0.0 \%)$ & $4^{\prime}(14.5 \%)$ & $12(0.0 \%)$ & $12^{\prime}(0.0 \%)$ \\
\hline & Koehler 2018 & $2 / 1$ & $2(0.0 \%)$ & $2(80.0 \%)$ & $3^{\prime}(72.4 \%)$ & $3(0.0 \%)$ & $4^{\prime \prime}(0.0 \%)$ & $3(24.2 \%)$ & $2(85.5 \%)$ & $5^{\prime \prime}(0.0 \%)$ & $4^{\prime}(0.0 \%)$ \\
\hline & Sas 2018 & $14 / 2$ & $0(100 \%)$ & $3(0.0 \%)$ & $3^{\prime}(37.9 \%)$ & $2(0.0 \%)$ & $3(73.3 \%)$ & $3^{\prime}(51.5 \%)$ & $2(82.9 \%)$ & $2(50.0 \%)$ & $7(0.0 \%)$ \\
\hline $\begin{array}{l}\text { Sybr } \\
\text { Green }\end{array}$ & $\begin{array}{l}\text { Schneeberger } \\
2017\end{array}$ & 2 & $6^{\prime}(0.0 \%)$ & $6^{\prime}(0.0 \%)$ & $3^{\prime}(17.2 \%)$ & $3(0.0 \%) *$ & $5^{\prime}(0.0 \%)$ & $\begin{array}{c}2^{\prime \prime} \\
(27.3 \%)\end{array}$ & $7^{\prime}(0.0 \%)$ & $9^{\prime}(0.0 \%)$ & $4(0.0 \%)$ \\
\hline LAMP & Osmann 2013 & 8 & $\begin{array}{c}24^{\prime \prime} \\
(0.0 \%)\end{array}$ & $23^{\prime}(0.0 \%)$ & $8^{\prime \prime}(6.9 \%)$ & $19^{\prime}(0.0 \%)$ & $\begin{array}{c}19^{\prime \prime} \\
(0.0 \%)\end{array}$ & $\begin{array}{c}23 " \\
(0.0 \%)\end{array}$ & $\begin{array}{c}21^{\prime \prime} \\
(0.0 \%)\end{array}$ & $\begin{array}{c}28^{\prime \prime} \\
(0.0 \%)\end{array}$ & $25^{\prime}(0.0 \%)$ \\
\hline
\end{tabular}

* Spain sequence (Africa 4) not available at forward primer binding site; ' One mismatch found at the last 5 nt of $3^{\prime}$ primers; " Two or more mismatches found at the last $5 \mathrm{nt}$ of $3^{\prime}$ primers; N: number of sequences used as target. 
Table 3. Scoring summary of the molecular assays with an annealing site lying in the extreme 5' or 3' non-coding regions.

\begin{tabular}{|c|c|c|c|c|c|c|c|c|c|c|c|}
\hline Type & Assay & Number of Primers/Probes & & & & & Clade & & & & \\
\hline & & & Africa 1 & Africa 2 & Africa 3 & Africa 4 & Asia 1 & Asia 2 & Europe 1 & Europe 2 & Europe 3 \\
\hline \multirow{3}{*}{ PCR } & \multirow{3}{*}{ Deyde 2006} & \multirow{3}{*}{2 primers } & $N=2$ & $N=1$ & $N=15$ & $N=0$ & $N=16$ & $N=20$ & $N=33$ & $N=2$ & $N=0$ \\
\hline & & & $0(100.0 \%)$ & $0(100.0 \%)$ & $1(93.3 \%)$ & $-(-)$ & $9(87.5 \%)$ & $2 "(90.0 \%)$ & $1(90.9 \%)$ & $0(100.0 \%)$ & $-(-)$ \\
\hline & & & $N=2$ & $N=2$ & $N=21$ & $N=0$ & $N=17$ & $N=24$ & $N=33$ & $N=2$ & $N=0$ \\
\hline \multirow[t]{2}{*}{ RealTime } & \multirow[t]{2}{*}{ Atkinson 2012} & \multirow[t]{2}{*}{2 primers / 1 probe } & $3(0.0 \%)$ & $6(0.0 \%)$ & $3(0.0 \%)$ & $-(-)$ & $15^{\prime}(0.0 \%)$ & $6(0.0 \%)$ & $5(0.0 \%)$ & $5(0.0 \%)$ & $-(-)$ \\
\hline & & & $N=2$ & $N=4$ & $N=27$ & $N=1$ & $N=21$ & $N=29$ & $N=72$ & $N=2$ & $N=2$ \\
\hline \multirow[t]{2}{*}{ RealTime } & \multirow[t]{2}{*}{ Kamboj 2014} & \multirow[t]{2}{*}{2 primers / 1 probe } & $7^{\prime}(0.0 \%)$ & $12^{\prime \prime}(0.0 \%)$ & $5^{\prime \prime}(0.0 \%)$ & $7^{\prime \prime}(0.0 \%)$ & $8^{\prime \prime}(0.0 \%)$ & $3^{\prime \prime}(24.1 \%)$ & $9^{\prime \prime}(0.0 \%)$ & $8 "(0.0 \%)$ & $15^{\prime \prime}(0.0 \%)$ \\
\hline & & & $N=2$ & $N=2$ & $N=22$ & $N=0$ & $N=19$ & $N=24$ & $N=58$ & $N=2$ & $N=0$ \\
\hline RPA & Bonney 2017 & 2 primers / 1 probe & $9^{\prime}(0.0 \%)$ & $11(0.0 \%)$ & $8^{\prime}(0.0 \%)$ & $-(-)$ & $10(0.0 \%)$ & $9(0.0 \%)$ & $5(46.6 \%)$ & $11(0.0 \%)$ & $-(-)$ \\
\hline
\end{tabular}

' One mismatch found at the last $5 \mathrm{nt}$ of 3' primers; " Two or more mismatches found at the last $5 \mathrm{nt}$ of 3 ' primers; N: number of sequences used as target. 
As reported in Table 4, using a combination of assays resulted in a better match with sequences owing to all sub-groups, except Africa 1, Europe 2, and Europe 3. Assay combinations tested for all CCHFV sequences was also reported, using a maximum of five assays since the use of more than five tests is excessively demanding from a computational and a practical point of view. For all clades analyzed, combining more than three tests did not improve detection efficacy.

Table 4. Best assay combinations for the CCHFV detection. For each clade, the combination(s) of assays with the best detection efficacy was reported on the basis of the three threshold parameters (see Methods).

\begin{tabular}{|c|c|c|c|c|c|c|}
\hline \multicolumn{2}{|c|}{ Clade } & $\begin{array}{c}\text { Best Assay Combination } \\
\text { Negredo } 2017\end{array}$ & $\begin{array}{l}\text { Equivalent Combination } \\
\text { Yapar } 2005 \text { OR Sas } 2018\end{array}$ & $\begin{array}{c}\text { Max } \\
\text { Mismatches } \\
\text { Per Seq }\end{array}$ & $\begin{array}{c}\text { Max } \\
\text { Mismatches } \\
\text { in Last } 5 \text { nt }\end{array}$ & $\begin{array}{c}\begin{array}{c}\text { Perfect } \\
\text { Matched } \\
\text { Sequences }\end{array} \\
100.0 \% \\
\end{array}$ \\
\hline Africa 2 & $N=5$ & Yapar 2005 + Koehler 2018 & & 1 & 0 & $80.0 \%$ \\
\hline Africa 3 & $N=29$ & Elata 2011 + Negredo 2017 & & 0 & 0 & $100.0 \%$ \\
\hline Asia 2 & $N=33$ & $\begin{array}{l}\text { Midilli } 2007 \text { + Schneeberger } \\
2017 \text { + Drosten } 2002\end{array}$ & $\begin{array}{c}\text { Midilli } 2007 \text { + Schneeberger } \\
2017 \text { + Kamboj } 2014 \text { OR } \\
\text { Negredo } 2017 \text { + Schneeberger } \\
2017 \text { + Kamboj } 2014 \text { OR } \\
\text { Negredo } 2017 \text { + Schneeberger } \\
2017 \text { + Drosten } 2002\end{array}$ & 0 & 0 & $100.0 \%$ \\
\hline Europe 2 & $N=2$ & Negredo 2017 & & 0 & 0 & $100.0 \%$ \\
\hline Europe 3 & $N=2$ & Yapar 2005 & & 1 & 0 & $0.0 \%$ \\
\hline All & $N=181$ & $\begin{array}{c}\text { Yapar } 2005 \text { + Negredo } 2017 \\
\text { + Koehler } 2018 \text { + Drosten } \\
2002 \text { + Wolfel } 2009\end{array}$ & & 1 & 0 & $93.4 \%$ \\
\hline
\end{tabular}

\section{Discussion}

An early and accurate diagnosis of CCHF infections is essential for case management and infection control procedures. The application of molecular tests in different settings is hampered by the great degree of sequence diversity. Therefore, serological methods have a broader use. The gold standard for diagnosis, however, is a combination of serology with molecular tests [4].

All available assays can be affected by the high diversity of the CCHFV genomes that hinders the design of specific primers/probe sets and prompts the use of high multiplexing procedures. Older molecular methods were designed on the basis of a limited number of CCHFV sequences and were often tested on a limited number of clades, while more recent assays were performed using bigger and updated data and were tested for multiple strain detection. Moreover, the methods optimized for the detection of strains circulating in a specific geographic area, might present a lower detection limit on the targeted strains, when compared with methods aimed to cover a broader spectrum of viral variants.

The in-silico PCR analysis performed in this study confirmed that assay sensitivity potential is strongly correlated to the geographic area of virus origin and to the evolutionary history of CCHFV, although validation studies with clinical samples are needed to proof this assumption. For example, the so-called "Drosten 2002" method perfectly matches more than $60 \%$ of sequences belonging to sub-group Asia 2 (Clade IV), but does not perfectly match any sequence belonging to other clades. Therefore, this assay can be considered useful to detect CCHFV from Asia but could perform worse when used to detect CCHFV from other regions. Our analysis confirmed suitability of primer choices for some assays that were expressly designed to detect CCHFV specifically from Europe, such as Duh 2006 (sub-group Europe 1) and Midilli 2009 (B) (sub-group Europe 2). A strong association between the predicted assay sensitivity and geographic origin emerged for other methods, like Wolfel 
2007 (south-western Asia), Schneeberger 2017 (Central and Southern Africa, Spain, and Central Asia) and Jaaskelainen 2014 (Europe). Other assays seemed to be less affected by geographical variability, showing a good match with CCHFV strains belonging to different regions, such as Yapar 2005, Negredo 2017, Koheler 2018, and Sas 2018. In particular, even if specifically designed to detect Europe 2 sequences, Midilli 2007 (nested PCR) showed a good sequence homology with isolates from Asia, Africa, and European clades perfectly matching $75.9 \%$ to $84.8 \%$ of the considered CCHFV strains. For some assays (i.e., Deyde 2006, Atkinson 2012, and Bonney 2017), it is not feasible to perform a robust variant analysis using this tool because their target region includes the CCHFV $5^{\prime}$ end that is rarely sequenced and reported. Consequently, in silico evaluation on their diagnostic capacity are not supported by enough data. In particular, the assay from Deyde et al. (2006) covers both the $5^{\prime}$ and $3^{\prime}$ ends of the $S$ segment and needs to be evaluated for potential sensitivity problems.

All parameters considered are intended as an easy guide for selecting the most appropriate assay for diagnostic purposes, even if further wet lab analysis on a wide panel of reference strains and real clinical samples are necessary to evaluate the sensitivity and specificity of molecular tests. However, limited reference strains are available for testing, even through specialized repositories like EVAg (www.european-virus-archive.com), and very few clinical samples are available for tuning the diagnostic capabilities. Interestingly, it could be noted that there were some agreements of our analysis with the EQA on the molecular detection of CCHFV [54]; in particular for Duh 2006, which was not able to detect strains from Asia 1 and Africa 3 clades. Therefore, in-silico evaluation, even if not free of drawbacks, still provides useful data for the choice of the most appropriate molecular method(s) to detect CCHFV from different endemic regions of the world. This analysis could not comprehend commercial assays (such as Altona), as they do not share primer sequences. We also emphasized the need for public sharing of primer design and selections for commercially offered assays, as part of capacity-building for emerging infections.

In conclusion, from this work emerges a strong region-dependence of potential performances of all assays, in detecting CCHFV. As more and more CCHFV sequences become available, our future efforts will be involved in the design of diagnostic tests capable to detect all known circulating CCHFV clades. Future molecular methods could be based on multiple tests, designed to detect multiple CCHFV targets at a high sensitivity and specificity. Potential design approaches based on Microarray or other High Multiplexing Fast PCR might be investigated. Currently, although a single method is to be considered appropriate for "local" investigations or in outbreak conditions, when the performance of the adopted method for the detection of the circulating strain is known, an effective diagnostic of $\mathrm{CCHF}$ in patients from different geographical areas should rely on a panel of methods and a thorough epidemiologic investigation.

Supplementary Materials: The following are available online at http:/www.mdpi.com/1999-4915/11/10/953/s1, Figure S1: Detailed phylogenetic tree. Figure S2: Sequence variants of the CCHFV S segment versus each molecular assay. Table S1: Published molecular assays for CCHFV detection at December 2018. Table S2: CCHFV genetic distances between all analyzed CCHFV genomes, calculated using the Kimura-2-parameters model.

Author Contributions: Conceptualization, A.D.C.; formal analysis and software C.E.M.G; investigation, B.B.; resources, C.C.; data curation, M.P.S.-S.; writing-original draft preparation, C.E.M.G.; writing-review and editing, R.H. and C.B.E.M.R.; validation, A.M., I.C., and T.A.; supervision, A.P., R.G., and M.K.; project administration, G.I.; funding acquisition, M.R.C.

Funding: This research was supported by the following funds: Italian Ministry of Health, grants Ricerca Corrente-Linea 1; European Union, Joint Action Consumers, Health, Agriculture, and Food Executive Agency for Efficient response to highly dangerous and emerging pathogens at EU level no. 677066 (EMERGE); European Centre for Disease Prevention and Control (ECDC), EVD-LabNet Framework contract ECDC/2016/00; European Union, Horizon 2020 research and innovation program "European Virus Archive goes Global" no. 653316 (EVAg).

Conflicts of Interest: The authors declare no conflict of interest. The funders had no role in the design of the study; in the collection, analyses, or interpretation of data; in the writing of the manuscript, or in the decision to publish the results. 


\section{References}

1. WHO Roadmap for Research and Product Development against Crimean-Congo Haemorrhagic Fever (CCHF). Available online: http://www.who.int/blueprint/priority-diseases/key-action/cchf-draft-r-and-d-roadmap. pdf?ua=1 (accessed on 12 June 2019).

2. European Centre for Disease Prevention and Control. Public Health Risks Related to Communicable Diseases During the 2018 Hajj, Saudi Arabia, 19-24 August 2018-2 August 2018; ECDC: Stockholm, Sweden, 2018; Available online: https://ecdc.europa.eu/sites/portal/files/documents/risks-diseases-hajj-saudi-arabia-rapidrisk-assessment-24-august-2018.pdf (accessed on 12 June 2019).

3. Ergönül, Ö.; Keske, Ş.; Çeldir, M.G.; Kara, İ.A.; Pshenichnaya, N.; Abuova, G.; Blumberg, L.; Gönen, M. Systematic Review and Meta-analysis of Postexposure Prophylaxis for Crimean-Congo Hemorrhagic Fever Virus among Healthcare Workers. Emerg. Infect. Dis. 2018, 24, 1642-1648. [CrossRef] [PubMed]

4. Bartolini, B.; Gruber, C.E.; Koopmans, M.; Avšič, T.; Bino, S.; Christova, I.; Grunow, R.; Hewson, R.; Korukluoglu, G.; Lemos, C.M.; et al. Laboratory management of Crimean-Congo haemorrhagic fever virus infections: Perspectives from two European networks. Eurosurveillance 2019, 24. [CrossRef] [PubMed]

5. Bente, D.A.; Forrester, N.L.; Watts, D.M.; McAuley, A.J.; Whitehouse, C.A.; Bray, M. Crimean-Congo hemorrhagic fever: History, epidemiology, pathogenesis, clinical syndrome and genetic diversity. Antivir. Res. 2013, 100, 159-189. [CrossRef] [PubMed]

6. James, N. Bunyaviridae. In Fenner's Veterinary Virology; Elsevier: Amsterdam, The Netherlands, 2017; pp. 411-424. ISBN 978-0-12-800946-8.

7. Palomar, A.M.; Portillo, A.; Santibáñez, P.; Mazuelas, D.; Arizaga, J.; Crespo, A.; Gutiérrez, Ó.; Cuadrado, J.F.; Oteo, J.A. Crimean-Congo Hemorrhagic Fever Virus in Ticks from Migratory Birds, Morocco1. Emerg. Infect. Dis. 2013, 19, 260-263. [CrossRef] [PubMed]

8. Gargili, A.; Estrada-Peña, A.; Spengler, J.R.; Lukashev, A.; Nuttall, P.A.; Bente, D.A. The role of ticks in the maintenance and transmission of Crimean-Congo hemorrhagic fever virus: A review of published field and laboratory studies. Antivir. Res. 2017, 144, 93-119. [CrossRef]

9. Sadeuh-Mba, S.A.; Wansi, G.M.; Demanou, M.; Gessain, A.; Njouom, R. Serological evidence of rift valley fever Phlebovirus and Crimean-Congo hemorrhagic fever orthonairovirus infections among pygmies in the east region of Cameroon. Virol. J. 2018, 15, 63. [CrossRef] [PubMed]

10. Balinandi, S.; Patel, K.; Ojwang, J.; Kyondo, J.; Mulei, S.; Tumusiime, A.; Lubwama, B.; Nyakarahuka, L.; Klena, J.D.; Lutwama, J.; et al. Investigation of an isolated case of human Crimean-Congo hemorrhagic fever in Central Uganda, 2015. Int. J. Infect. Dis. 2018, 68, 88-93. [CrossRef]

11. Zehender, G.; Ebranati, E.; Shkjezi, R.; Papa, A.; Luzzago, C.; Gabanelli, E.; Lo Presti, A.; Lai, A.; Rezza, G.; Galli, M.; et al. Bayesian Phylogeography of Crimean-Congo Hemorrhagic Fever Virus in Europe. PLoS ONE 2013, 8, 79663. [CrossRef]

12. Emmerich, P.; Jakupi, X.; von Possel, R.; Berisha, L.; Halili, B.; Günther, S.; Cadar, D.; Ahmeti, S.; Schmidt-Chanasit, J. Viral metagenomics, genetic and evolutionary characteristics of Crimean-Congo hemorrhagic fever orthonairovirus in humans, Kosovo. Infect. Genet. Evol. 2018, 65, 6-11. [CrossRef]

13. Lukashev, A.N.; Deviatkin, A.A. Phylodynamics of Crimean Congo hemorrhagic fever virus in South Russia. Infect. Genet. Evol. 2018, 59, 23-27. [CrossRef]

14. Yadav, P.D.; Patil, D.Y.; Shete, A.M.; Kokate, P.; Goyal, P.; Jadhav, S.; Sinha, S.; Zawar, D.; Sharma, S.K.; Kapil, A.; et al. Nosocomial infection of CCHF among health care workers in Rajasthan, India. BMC Infect. Dis. 2016, 16, 624. [CrossRef] [PubMed]

15. Yadav, P.D.; Thacker, S.; Patil, D.Y.; Jain, R.; Mourya, D.T. Crimean-Congo Hemorrhagic Fever in Migrant Worker Returning from Oman to India, 2016. Emerg. Infect. Dis. 2017, 23, 1005-1008. [CrossRef] [PubMed]

16. Zhang, Y.; Shen, S.; Fang, Y.; Liu, J.; Su, Z.; Liang, J.; Zhang, Z.; Wu, Q.; Wang, C.; Abudurexiti, A.; et al. Isolation, Characterization, and Phylogenetic Analysis of Two New Crimean-Congo Hemorrhagic Fever Virus Strains from the Northern Region of Xinjiang Province, China. Virol. Sin. 2018, 33, 74-86. [CrossRef] [PubMed]

17. Moming, A.; Yue, X.; Shen, S.; Chang, C.; Wang, C.; Luo, T.; Zhang, Y.; Guo, R.; Hu, Z.; Zhang, Y.; et al. Prevalence and Phylogenetic Analysis of Crimean-Congo Hemorrhagic Fever Virus in Ticks from Different Ecosystems in Xinjiang, China. Virol. Sin. 2018, 33, 67-73. [CrossRef] 
18. Papa, A.; Chaligiannis, I.; Kontana, N.; Sourba, T.; Tsioka, K.; Tsatsaris, A.; Sotiraki, S. A novel AP92-like Crimean-Congo hemorrhagic fever virus strain, Greece. Ticks Tick-Borne Dis. 2014, 5, 590-593. [CrossRef]

19. Ozkaya, E.; Dincer, E.; Carhan, A.; Uyar, Y.; Ertek, M.; Whitehouse, C.A.; Ozkul, A. Molecular epidemiology of Crimean-Congo hemorrhagic fever virus in Turkey: Occurrence of local topotype. Virus Res. 2010, 149, 64-70. [CrossRef]

20. Estrada-Peña, A.; Palomar, A.M.; Santibáñez, P.; Sánchez, N.; Habela, M.A.; Portillo, A.; Romero, L.; Oteo, J.A. Crimean-Congo Hemorrhagic Fever Virus in Ticks, Southwestern Europe, 2010. Emerg. Infect. Dis. 2012, 18, 179-180. [CrossRef]

21. Negredo, A.; Habela, M.Á.; Ramírez de Arellano, E.; Diez, F.; Lasala, F.; López, P.; Sarriá, A.; Labiod, N.; Calero-Bernal, R.; Arenas, M.; et al. Survey of Crimean-Congo Hemorrhagic Fever Enzootic Focus, Spain, 2011-2015. Emerg. Infect. Dis. 2019, 25, 1177-1184. [CrossRef]

22. Negredo, A.; de la Calle-Prieto, F.; Palencia-Herrejón, E.; Mora-Rillo, M.; Astray-Mochales, J.; Sánchez-Seco, M.P.; Bermejo Lopez, E.; Menárguez, J.; Fernández-Cruz, A.; Sánchez-Artola, B.; et al. Autochthonous Crimean-Congo Hemorrhagic Fever in Spain. N. Engl. J. Med. 2017, 377, 154-161. [CrossRef]

23. ECDC Communicable Disease Threats Report (CDTR) Week 50, 9-15 December 2018. Available online: https://ecdc.europa.eu/sites/portal/files/documents/communicable-disease-threats-report18-aug-2018.pdf (accessed on 12 June 2019).

24. Papa, A.; Papadopoulou, E.; Tsioka, K.; Kontana, A.; Pappa, S.; Melidou, A.; Giadinis, N.D. Isolation and whole-genome sequencing of a Crimean-Congo hemorrhagic fever virus strain, Greece. Ticks Tick-Borne Dis. 2018, 9, 788-791. [CrossRef]

25. Corman, V.M.; Rasche, A.; Baronti, C.; Cadar, D.; Goorhuis, A.; Schinkel, J.; Molenkamp, R.; Bleicker, T.; Brünink, S.; Eschbach, M.; et al. Clinical comparison, standardization and optimization of Zika virus molecular detection. Bull. World Health Organ. 2016, 829, 27.

26. Lefever, S.; Pattyn, F.; Hellemans, J.; Vandesompele, J. Single-Nucleotide Polymorphisms and Other Mismatches Reduce Performance of Quantitative PCR Assays. Clin. Chem. 2013, 59, 1470-1480. [CrossRef] [PubMed]

27. Stadhouders, R.; Pas, S.D.; Anber, J.; Voermans, J.; Mes, T.H.M.; Schutten, M. The Effect of Primer-Template Mismatches on the Detection and Quantification of Nucleic Acids Using the $5^{\prime}$ Nuclease Assay. J. Mol. Diagn. 2010, 12, 109-117. [CrossRef] [PubMed]

28. Basu, C. PCR Primer Design: Methods in Molecular Biology, 2nd ed.; Humana Press: New York, NY, USA, 2015; ISBN 978-1-4939-2364-9.

29. Kim, H.; Kang, N.; Chon, K.-W.; Kim, S.; Lee, N.; Koo, J.; Kim, M.-S. MRPrimer: A MapReduce-based method for the thorough design of valid and ranked primers for PCR. Nucleic Acids Res. 2015, 43, 130. [CrossRef] [PubMed]

30. Sanchez-Seco, M.P.; National Centre of Microbiology, Institute of Health "Carlos III", Majadahonda, 28220 Madrid, Spain. Personal communication, 2018.

31. Lukashev, A.N.; Klimentov, A.S.; Smirnova, S.E.; Dzagurova, T.K.; Drexler, J.F.; Gmyl, A.P. Phylogeography of Crimean Congo Hemorrhagic Fever Virus. PLoS ONE 2016, 11, 166744. [CrossRef]

32. Vanneste, K.; Garlant, L.; Broeders, S.; Van Gucht, S.; Roosens, N.H. Application of whole genome data for in silico evaluation of primers and probes routinely employed for the detection of viral species by RT-qPCR using dengue virus as a case study. BMC Bioinf. 2018, 19, 312. [CrossRef]

33. Cornish-Bowden, A. Nomenclature for incompletely specified bases in nucleic acid sequences: Recommendations 1984. Eur. J. Biochem. 1985, 13, 3021. [CrossRef]

34. Drosten, C.; Gottig, S.; Schilling, S.; Asper, M.; Panning, M.; Schmitz, H.; Gunther, S. Rapid Detection and Quantification of RNA of Ebola and Marburg Viruses, Lassa Virus, Crimean-Congo Hemorrhagic Fever Virus, Rift Valley Fever Virus, Dengue Virus, and Yellow Fever Virus by Real-Time Reverse Transcription-PCR. J. Clin. Microbiol. 2002, 40, 2323-2330. [CrossRef]

35. Deyde, V.M.; Khristova, M.L.; Rollin, P.E.; Ksiazek, T.G.; Nichol, S.T. Crimean-Congo Hemorrhagic Fever Virus Genomics and Global Diversity. J. Virol. 2006, 80, 8834-8842. [CrossRef]

36. Schwarz, T.F.; Longson, M.; Shurie, H.; Acharya, U.G.; Gilch, S.; Zahir, A.R.M.; Nitschko, H.; Ameen, A.; Nsanze, H.; Jager, G. Polymerase Chain Reaction for Diagnosis and Identification of Distinct Variants of Crimean-Congo Hemorrhagic Fever Virus in the United Arab Emirates. Am. J. Trop. Med. Hyg. 1996, 55, 190-196. [CrossRef] 
37. Midilli, K.; Gargılı, A.; Ergonul, O.; Şengöz, G.; Ozturk, R.; Bakar, M.; Jongejan, F. Imported Crimean-Congo hemorrhagic fever cases in Istanbul. BMC Infect. Dis. 2007, 7, 54. [CrossRef] [PubMed]

38. Midilli, K.; Gargılı, A.; Ergonul, O.; Elevli, M.; Ergin, S.; Turan, N.; Şengöz, G.; Ozturk, R.; Bakar, M. The first clinical case due to AP92 like strain of Crimean-Congo Hemorrhagic Fever virus and a field survey. BMC Infect. Dis. 2009, 9, 90. [CrossRef] [PubMed]

39. Elata, A.T.; Karsany, M.S.; Elageb, R.M.; Hussain, M.A.; Eltom, K.H.; Elbashir, M.I.; Aradaib, I.E. A nosocomial transmission of crimean-congo hemorrhagic fever to an attending physician in north kordufan, Sudan. Virol. J. 2011, 8, 303. [CrossRef] [PubMed]

40. Yapar, M.; Aydogan, H.; Pahsa, A.; Besirbellioglu, B.A.; Bodur, H.; Basustaoglu, A.C.; Guney, C.; Avci, I.Y.; Sener, K.; Setteh, M.H.A.; et al. Rapid and Quantitative Detection of Crimean-Congo Hemorrhagic Fever Virus by One-Step Real-Time Reverse Transcriptase-PCR. Jpn. J. Infect. Dis. 2005, 58, 358.

41. Duh, D.; Saksida, A.; Petrovec, M.; Dedushaj, I.; Avšič-Županc, T. Novel one-step real-time RT-PCR assay for rapid and specific diagnosis of Crimean-Congo hemorrhagic fever encountered in the Balkans. J. Virol. Methods 2006, 133, 175-179. [CrossRef]

42. Garrison, A.R.; Alakbarova, S.; Kulesh, D.A.; Khodjaev, S.; Endy, T.P.; Shezmukhamedova, D.; Paragas, J. Development of a TaqMan ${ }^{\circledR}$ _-Minor Groove Binding Protein Assay for the Detection and Quantification of Crimean-Congo Hemorrhagic Fever Virus. Am. J. Trop. Med. Hyg. 2007, 77, 514-520. [CrossRef]

43. Wölfel, R.; Paweska, J.T.; Petersen, N.; Grobbelaar, A.A.; Leman, P.A.; Hewson, R.; Georges-Courbot, M.-C.; Papa, A.; Günther, S.; Drosten, C. Virus Detection and Monitoring of Viral Load in Crimean-Congo Hemorrhagic Fever Virus Patients. Emerg. Infect. Dis. 2007, 13, 1097-1100. [CrossRef]

44. Wolfel, R.; Paweska, J.T.; Petersen, N.; Grobbelaar, A.A.; Leman, P.A.; Hewson, R.; Georges-Courbot, M.-C.; Papa, A.; Heiser, V.; Panning, M.; et al. Low-Density Macroarray for Rapid Detection and Identification of Crimean-Congo Hemorrhagic Fever Virus. J. Clin. Microbiol. 2009, 47, 1025-1030. [CrossRef]

45. Atkinson, B.; Chamberlain, J.; Logue, C.H.; Cook, N.; Bruce, C.; Dowall, S.D.; Hewson, R. Development of a Real-Time RT-PCR Assay for the Detection of Crimean-Congo Hemorrhagic Fever Virus. Vector-Borne Zoonotic Dis. 2012, 12, 786-793. [CrossRef]

46. Jääskeläinen, A.J.; Kallio-Kokko, H.; Ozkul, A.; Bodur, H.; Korukruoglu, G.; Mousavi, M.; Pranav, P.; Vaheri, A.; Mirazimi, A.; Vapalahti, O. Development and Evaluation of a Real-Time RT-qPCR for Detection of Crimean-Congo Hemorrhagic Fever Virus Representing Different Genotypes. Vector-Borne Zoonotic Dis. 2014, 14, 870-872. [CrossRef]

47. Kamboj, A.; Pateriya, A.K.; Mishra, A.; Ranaware, P.; Kulkarni, D.D.; Raut, A.A. Novel Molecular Beacon Probe-Based Real-Time RT-PCR Assay for Diagnosis of Crimean-Congo Hemorrhagic Fever Encountered in India. BioMed Res. Int. 2014, 2014, 1-4. [CrossRef]

48. Pang, Z.; Li, A.; Li, J.; Qu, J.; He, C.; Zhang, S.; Li, C.; Zhang, Q.; Liang, M.; Li, D. Comprehensive Multiplex One-Step Real-Time TaqMan qRT-PCR Assays for Detection and Quantification of Hemorrhagic Fever Viruses. PLoS ONE 2014, 9, 95635. [CrossRef] [PubMed]

49. Koehler, J.W.; Delp, K.L.; Hall, A.T.; Olschner, S.P.; Kearney, B.J.; Garrison, A.R.; Altamura, L.A.; Rossi, C.A.; Minogue, T.D. Sequence Optimized Real-Time Reverse Transcription Polymerase Chain Reaction Assay for Detection of Crimean-Congo Hemorrhagic Fever Virus. Am. J. Trop. Med. Hyg. 2018, 98, 211-215. [CrossRef]

50. Sas, M.A.; Vina-Rodriguez, A.; Mertens, M.; Eiden, M.; Emmerich, P.; Chaintoutis, S.C.; Mirazimi, A.; Groschup, M.H. A one-step multiplex real-time RT-PCR for the universal detection of all currently known CCHFV genotypes. J. Virol. Methods 2018, 255, 38-43. [CrossRef] [PubMed]

51. Schneeberger, P.H.H.; Pothier, J.F.; Bühlmann, A.; Duffy, B.; Beuret, C.; Utzinger, J.; Frey, J.E. Development and evaluation of a bioinformatics approach for designing molecular assays for viral detection. PLoS ONE 2017, 12, 178195. [CrossRef] [PubMed]

52. Osman, H.A.M.; Eltom, K.H.; Musa, N.O.; Bilal, N.M.; Elbashir, M.I.; Aradaib, I.E. Development and evaluation of loop-mediated isothermal amplification assay for detection of Crimean Congo hemorrhagic fever virus in Sudan. J. Virol. Methods 2013, 190, 4-10. [CrossRef] [PubMed] 
53. Bonney, L.C.; Watson, R.J.; Afrough, B.; Mullojonova, M.; Dzhuraeva, V.; Tishkova, F.; Hewson, R. A recombinase polymerase amplification assay for rapid detection of Crimean-Congo Haemorrhagic fever Virus infection. PLoS Negl. Trop. Dis. 2017, 11, 6013. [CrossRef] [PubMed]

54. Escadafal, C.; Ölschläger, S.; Avšič-Županc, T.; Papa, A.; Vanhomwegen, J.; Wölfel, R.; Mirazimi, A.; Teichmann, A.; Donoso-Mantke, O.; Niedrig, M. First International External Quality Assessment of Molecular Detection of Crimean-Congo Hemorrhagic Fever Virus. PLoS Negl. Trop. Dis. 2012, 6, 1706. [CrossRef]

(C) 2019 by the authors. Licensee MDPI, Basel, Switzerland. This article is an open access article distributed under the terms and conditions of the Creative Commons Attribution (CC BY) license (http://creativecommons.org/licenses/by/4.0/). 